\title{
Time Trends of the Incidence, Prevalence, and Mortality of Parkinsonism
}

\author{
Jessica J. Wong, Jeffrey C. Kwong, Karen Tu, Debra A. Butt, Ray Copes, \\ Andrew S. Wilton, Brian J. Murray, Alexander Kopp, Hong Chen
}

\begin{abstract}
Objectives: We assessed trends in the incidence, prevalence, and post-diagnosis mortality of parkinsonism in Ontario, Canada over 18 years. We also explored the influence of a range of risk factors for brain health on the trend of incident parkinsonism. Methods: We established an open cohort by linking population-based health administrative databases from 1996 to 2014 in Ontario. The study population comprised residents aged 20-100 years with an incident diagnosis of parkinsonism ascertained using a validated algorithm. We calculated ageand sex-standardized incidence, prevalence, and mortality of parkinsonism, stratified by young onset (20-39 years) and mid/late onset ( $\geq 40$ years). We assessed trends in incidence using Poisson regression, mortality using negative binomial regression, and prevalence of parkinsonism and pre-existing conditions (e.g., head injury) using the Cochran-Armitage trend test. To better understand trends in the incidence of mid/lateonset parkinsonism, we adjusted for various pre-existing conditions in the Poisson regression model. Results: From 1996 to 2014, we identified 73,129 incident cases of parkinsonism (source population of $\sim 10.5$ million), of whom $56 \%$ were male, mean age at diagnosis was 72.6 years, and $99 \%$ had mid/late-onset parkinsonism. Over 18 years, the age- and sex-standardized incidence decreased by $13.0 \%$ for mid/late-onset parkinsonism but remained unchanged for young-onset parkinsonism. The age- and sex-standardized prevalence increased by $22.8 \%$, while post-diagnosis mortality decreased by 5.5\%. Adjustment for pre-existing conditions did not appreciably explain the declining incidence of mid/ late-onset parkinsonism. Conclusion: Young-onset and mid/late-onset parkinsonism exhibited differing trends in incidence over 18 years in Ontario. Further research to identify other factors that may appreciably explain trends in incident parkinsonism is warranted.
\end{abstract}

RÉSUMÉ: Tendances temporelles de l'incidence, de la prévalence et du taux de mortalité du parkinsonisme. Objectifs: Au cours d'une période de 18 ans, nous avons tenté d'évaluer en Ontario (Canada) diverses tendances du parkinsonisme, qu'il s'agisse de l'incidence et de la prévalence de cette maladie mais également du taux de mortalité suivant un diagnostic. Nous avons aussi exploré le rôle d'un éventail de facteurs de risque liés à la santé du cerveau en relation avec la tendance à voir de nouveaux cas de parkinsonisme apparaitre. Méthodes: Aux fins de cette étude, nous avons établi une cohorte ouverte en liant entre elles des bases de données administratives du domaine de la santé, et ce, pour les années 1996 à 2014. La population à l'étude comprenait des résidents de l'Ontario âgés de 20 à 100 ans chez qui l'on avait diagnostiqué, au moyen d'un algorithme préalablement validé, les premiers signes de parkinsonisme. Une fois les variables du sexe et de l'âge standardisées, nous avons par la suite calculé l'incidence, la prévalence et le taux de mortalité du parkinsonisme en stratifiant nos cas en fonction d'un âge précoce (20 à 39 ans) ou d'un âge intermédiaire/avancé ( $\geq$ de 40 ans). Au moyen de la régression de Poisson, nous avons évalué les tendances en matière d'incidence; dans le cas du taux de mortalité, nous nous sommes basés sur une régression binomiale négative; enfin, tant la prévalence du parkinsonisme que des conditions préexistantes (par exemple des blessures à la tête) ont été évaluées à l'aide du test de tendance Cochran-Armitage. Afin de mieux comprendre les tendances liées à l'incidence du parkinsonisme apparaissant à un âge intermédiaire/avancé, nous avons effectué des ajustements dans le modèle de régression de Poisson en tenant compte de nombreuses conditions préexistantes. Résultats: De 1996 à 2014, nous avons identifié 73129 nouveaux cas de parkinsonisme au sein d'une population d'environ 10,5 millions d'individus. $56 \%$ des sujets atteints de cette maladie étaient de sexe masculin. Ajoutons aussi que leur âge moyen au moment d'un diagnostic était de 72,6 ans et que $99 \%$ d'entre eux étaient atteints de parkinsonisme s'étant développé à un âge intermédiaire/avancé. Au cours de cette période de 18 ans, l'incidence standardisée en fonction de l'âge et du sexe a diminué de $13,0 \%$ en ce qui concerne le parkinsonisme apparu à un âge intermédiaire/avancé. Elle est néanmoins demeurée inchangée pour ce qui est du parkinsonisme apparu à un âge précoce. La prévalence standardisée en fonction de l'âge et du sexe a quant à elle augmenté de $22,8 \%$ alors que le taux de mortalité suivant un diagnostic a baissé de 5,5\%. Nos ajustements tenant compte de conditions préexistantes n'ont pas permis d'expliquer de façon satisfaisante l'incidence en baisse du parkinsonisme apparu à un âge intermédiaire/avancé. Conclusions: Qu'il s'agisse de parkinsonisme apparaissant à un âge précoce ou à un âge intermédiaire/avancé, on a pu observer différentes tendances en matière d'incidence au cours de cette période de 18 ans. Des recherches plus poussées permettant d'identifier d'autres facteurs pouvant expliquer de façon plus sensible ces tendances sont ainsi justifiées.

Keywords: Parkinsonism, Parkinson's disease, Incidence, Mortality, Epidemiology

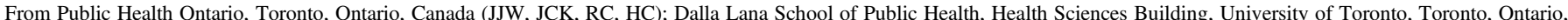

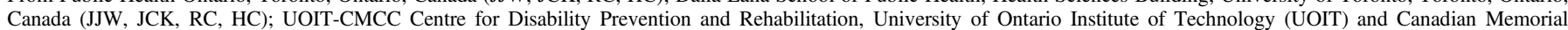

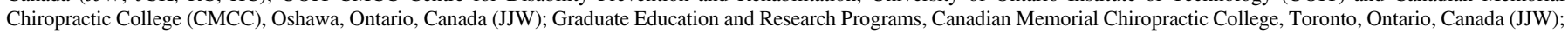

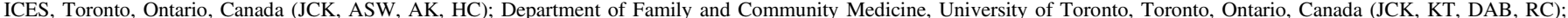

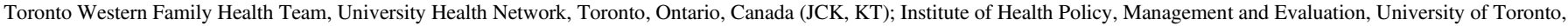

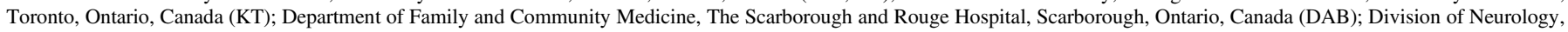
Department of Medicine, Sunnybrook Health Sciences Centre, University of Toronto, Toronto, Ontario, Canada (BJM)

Received September 2, 2018. Final Revisions Submitted November 7, 2018. Date of Acceptance November 25, 2018.

Correspondence to: Hong Chen, Public Health Ontario, 480 University Avenue, Toronto, Ontario M5G 1V2, Canada. Email: hong.chen@oahpp.ca 


\section{INTRODUCTION}

Parkinsonism is a leading cause of neurological disability worldwide, associated with impaired work capacity, quality of life, and survival. ${ }^{1-4}$ Parkinsonism is also costly to society. ${ }^{1,5-7}$ Since parkinsonism can affect younger adults, understanding the timing and trends of disease onset (young vs. mid/late-onset) has important clinical implications on etiology and prognosis. ${ }^{8,9}$ Genetic forms of parkinsonism ( 2\% of sporadic, $\sim 10 \%$ of familial cases) would more likely present in younger patients and be less prone to change over time. ${ }^{10,11}$

The World Health Organization emphasized a need for upto-date information about the burden of parkinsonism and Parkinson's disease. ${ }^{2,8}$ However, studies have found different trends in the incidence of parkinsonism and Parkinson's disease. For Parkinson's disease, two studies reported relatively stable incidence, ${ }^{12,13}$ three studies reported decreasing incidence, ${ }^{14-16}$ and two studies reported increasing incidence. ${ }^{17,18}$ For parkinsonism, one study reported relatively unchanged incidence trends over time,${ }^{19}$ while one study reported decreasing incidence. ${ }^{20}$ Less is known about the prevalence and mortality trends of parkinsonism ${ }^{21}$ or Parkinson's disease. ${ }^{13,16,22-24}$ Since most studies analyzed data collected prior to $2010,{ }^{16,21-23}$ whether these trends persist in recent years remains unknown. It has been hypothesized that parkinsonism incidence is decreasing while prevalence is increasing over time, similar to trends for other neurodegenerative pathologies. ${ }^{25}$

Understanding the incidence and mortality of parkinsonism will enable quantification of disease burden to establish priorities. Characterizing the prevalence of pre-existing conditions as accepted or suspected risk factors will further inform future hypotheses on the development of parkinsonism. Thus, we conducted a large population-based study to determine time trends of the incidence, prevalence, and post-diagnosis mortality of parkinsonism in Ontario, Canada from 1996 to 2014. We also explored the influence of risk factors for brain health on trends of incident parkinsonism during this period.

\section{Methods}

\section{Study Design and Population}

We established a retrospective cohort in Ontario, Canada by linking population-based health administrative and vital statistics databases using unique encoded identifiers and analyzed at ICES. This cohort included all Ontario residents who, from 1991 to 2013 fiscal years (i.e., April 1, 1991 to March 31, 2014), were (1) aged 20-100 years, (2) registered with the provincial health insurance plan (Ontario Health Insurance Plan (OHIP)) for at least 5 years, and (3) diagnosed with incident parkinsonism.

\section{Standard Protocol Approvals, Registrations, and Patient Consents}

Ethical approval for the study was obtained from the Sunnybrook Health Sciences Centre Research Ethics Board (\#1592014). The full dataset creation plan is available from the authors upon request.

\section{Data Sources}

We assembled this cohort using the Ontario's Registered Persons Database, a registry of all Ontario residents who have ever had provincial health insurance. ${ }^{26}$ In addition, we used the following databases to ascertain incident cases of parkinsonism: (1) OHIP for physician billing claims and (2) Ontario Drug Benefits (ODB) for prescription medication claims (for those aged 65 and older). To obtain information on demographics and risk factors (accepted or suspected) of parkinsonism, we used the following: (1) National Ambulatory Care Reporting System (emergency department data); (2) Canadian Census; and (3) administrative database algorithms for diabetes, congestive heart failure, chronic obstructive pulmonary disease (COPD), traumatic brain injury, dementia, and hypertension. ${ }^{27-31}$ Furthermore, we used the Office of the Registrar General Deaths database to obtain death data among persons diagnosed with parkinsonism. These databases cover virtually the entire Ontario population. ${ }^{27}$

\section{Case Ascertainment for Parkinsonism}

To ascertain incident cases of parkinsonism, we applied a validated algorithm to the OHIP and ODB databases. ${ }^{32}$ Specifically, parkinsonism was determined based on one physician claim with a diagnostic code for parkinsonism and one drug claim for a medication used to treat parkinsonism within a 6-month period, or two physician claims within a 1-year period. The algorithm was previously validated and shown to have a sensitivity of $78.4 \%$, specificity of $99.9 \%$, positive predictive value of $75.4 \%$, and negative predictive value of $99.9 \% .^{32}$

\section{Selected Risk Factors of Newly Diagnosed Parkinsonism}

To better understand trends in the incidence of parkinsonism (especially $\mathrm{mid} / \mathrm{late}$-onset), we selected a wide array of health conditions that are either accepted or suspected risk factors for some forms of parkinsonism. ${ }^{33-39} \mathrm{We}$ ascertained all selected medical factors among persons with parkinsonism over a 5-year period before the diagnosis, with the exception of dementia, which was ascertained since $1991 .^{27}$ To ascertain dementia, diabetes, traumatic brain injury, hypertension, COPD, and congestive heart failure, we used data on hospital discharges, physician office visits, and emergency room visits with administrative database algorithms, as used in previous studies (Table 1). ${ }^{28-31}$ We used hospitalization data to ascertain the presence of stroke and coronary artery disease. Finally, we used survey data from Farm and Food Care Ontario to ascertain pesticide use and the Canadian Community Health Survey to ascertain smoking in the general population. ${ }^{40}$

\section{Analysis}

We described the cohort of incident cases of parkinsonism with respect to sex, age at diagnosis, income quintile, residence, and onset of parkinsonism, using means (standard deviations) and percentages to report continuous and dichotomous variables, respectively.

\section{Annual Incidence, Prevalence, and Mortality Rate}

We calculated both crude and standardized (by age and sex) incidence, prevalence, and mortality each year between 1996 and 2013 fiscal years (i.e., starting on April 1). To calculate annual incidence, we used newly diagnosed cases of parkinsonism as 
Table 1: Administrative database algorithms to ascertain selected risk factors among persons with parkinsonism

\begin{tabular}{|c|c|c|c|}
\hline Risk factor & Description & Sensitivity \% & Specificity \% \\
\hline $\mathrm{COPD}^{29}$ & One or more ambulatory claims and/or one or more hospitalizations for COPD & 85 & 79 \\
\hline $\begin{array}{l}\text { Congestive heart } \\
\text { failure }^{31}\end{array}$ & $\begin{array}{l}\text { Aged }>40 \text { years and either one hospital admission with a congestive heart failure diagnosis or one OHIP } \\
\text { claim/emergency department record with a congestive heart failure diagnosis followed within } 1 \text { year by a } \\
\text { second record from either source or one hospital admission }\end{array}$ & 85 & 97 \\
\hline Dementia $^{27}$ & $\begin{array}{l}\text { Aged }>20 \text { years and either one hospital admission with a diagnosis of dementia or at least three OHIP claims } \\
\text { for dementia within } 2 \text { years or at least one prescription for drugs relating to dementia }\end{array}$ & 75 & 99 \\
\hline Diabetes mellitus ${ }^{30}$ & $\begin{array}{l}\text { Either one hospital admission with diabetes mellitus diagnosis or an OHIP claim followed within } 2 \text { years by } \\
\text { either an OHIP claim or a hospital admission with diabetes mellitus diagnosis }\end{array}$ & 86 & 97 \\
\hline Hypertension $^{28}$ & $\begin{array}{l}\text { Either one hospital admission with a hypertension diagnosis or an OHIP claim with a hypertension diagnosis } \\
\text { followed within } 2 \text { years by either an OHIP claim or a hospital admission for hypertension }\end{array}$ & 72 & 95 \\
\hline $\begin{array}{l}\text { Traumatic brain } \\
\text { injury }^{\mathrm{a} 41}\end{array}$ & One hospitalization record or one emergency department visit record for traumatic brain injury & Not available & Not available \\
\hline
\end{tabular}

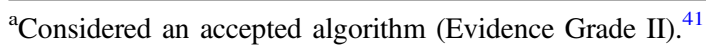

$\mathrm{COPD}=$ chronic obstructive pulmonary disease; OHIP $=$ Ontario Health Insurance Plan.

the numerator and person-years at risk (i.e., excluding prevalent cases) as the denominator. Similarly, we calculated annual prevalence using prevalent cases of parkinsonism who were alive and lived in Ontario at the beginning of each fiscal year as the numerator and the entire Ontario population aged 20-100 years as the denominator. We calculated annual all-cause mortality rate from persons who lived with parkinsonism at the beginning of each year. To obtain age- and sex-standardized incidence and prevalence, we used 2001 Census data for the Ontario population on July 1 of each year. ${ }^{42}$ We standardized post-diagnosis mortality using all Ontario residents living with parkinsonism in 2005 as the reference. We selected this reference (rather than using 2001 Census data for the Ontario population) because the age and sex distribution of individuals with parkinsonism are distinctly different from the general population. All analyses were conducted by young-onset (aged 20-39 years) and mid/late-onset parkinsonism (aged $\geq 40$ years) separately, according to the World Health Organization. ${ }^{8}$ We also stratified incidence and prevalence by sex.

Lastly, we estimated the annual prevalence of selected risk factors for brain health (i.e., stroke, traumatic brain injury, diabetes, dementia, hypertension, congestive heart failure, coronary artery disease, and COPD) among persons with a new diagnosis of parkinsonism and among the general population during the study period, respectively.

\section{Time Trend Analysis}

To characterize time trends of incidence and mortality of parkinsonism, we used Poisson and negative binomial regression models, respectively. To assess time trends in mortality, we applied negative binomial regression that accounted for zero counts. ${ }^{17,43}$ In all the models, we adjusted for year (continuous variable), age group (ordinal variable: 5-year intervals between 20 and 89 years, and $\geq 90$ years), and sex (categorical variable), with person-years as the offset.

We also used the two-sided Cochran-Armitage trend test to evaluate time trends of the age- and sex-standardized prevalence and the above-mentioned risk factors of parkinsonism over four equal-interval epochs: 1998-2001 (epoch 1), 2002-2005 (epoch 2), 2006-2009 (epoch 3), and 2010-2013 (epoch 4). We computed the average prevalence in each epoch to assess these time trends. Furthermore, we performed Poisson regression modeling to investigate trends in the incidence of mid/late-onset parkinsonism after accounting for prevalence of the abovementioned risk factors derived in persons with parkinsonism and in the general population, respectively. We also adjusted for rural residence among persons with parkinsonism and the prevalence of smoking and pesticide use in the general population. Statistical significance was set at an alpha level of 0.05 .

\section{Results}

\section{Characteristics of Incident Parkinsonism}

From 1996 to 2014, we identified 73,129 incident cases of parkinsonism in Ontario (population 10.5 million in 2013), with $56 \%$ male and a mean age of 72.6 years at diagnosis (Table 2). The proportion of incident cases who were male increased from $53 \%$ in $1996 / 97$ to $58 \%$ in $2013 / 14$, whereas the mean age at diagnosis remained constant over the time period. Approximately 99\% of incident cases had mid/late-onset and $1 \%$ had youngonset parkinsonism in 2013/14. The proportion of patients living in higher income neighborhoods increased between 1996/97 and 2013/14.

\section{Age- and Sex-standardized Incidence, Prevalence, and Post-Diagnosis Mortality of Parkinsonism}

From 1996 to 2014, incidence remained relatively unchanged for young-onset parkinsonism $(p=0.7341)$ but decreased by $13.1 \%$ for $\mathrm{mid} / \mathrm{late}-$ onset parkinsonism $(p<0.0001)$ (Table 3 ; Figure 1A). When stratified by sex, the incidence of all parkinsonism decreased by $9.3 \%$ for males $(p<0.0001)$ and $17.5 \%$ for females $(p<0.0001)$.

Prevalence increased by $22.8 \%$ over the 18 years $(p<0.0001)$, with similar increasing trends among those with young-onset and mid/late-onset parkinsonism (Table 3; Figure 1B). The prevalence of parkinsonism increased by $21.9 \%$ for males $(p<0.0001)$ and $23.8 \%$ for females $(p<0.0001)$.

Mortality rate among individuals living with parkinsonism decreased by $5.5 \%(p=0.0180)$ over the 18 years, with similar decreasing trends for both young-onset and mid/late-onset parkinsonism (Table 3; Figure 1C). 
Table 2: Characteristics of persons with incident parkinsonism (including Parkinson's disease) aged 20 years and older in Ontario, Canada, from 1996/97 to 2013/14

\begin{tabular}{|c|c|c|c|}
\hline Characteristic & $\begin{array}{l}\text { Entire study } \\
\quad \text { period }\end{array}$ & $1996 / 97$ & 2013/14 \\
\hline & $N=73,129$ & $N=3461$ & $N=4791$ \\
\hline \multicolumn{4}{|l|}{ Sex, $n(\%)$} \\
\hline Female & $32,575(44.5)$ & $1621(46.8)$ & 1999 (41.7) \\
\hline Male & $40,554(55.5)$ & $1840(53.2)$ & $2792(58.3)$ \\
\hline $\begin{array}{l}\text { Age at diagnosis } \\
\text { (years), mean (SD) }\end{array}$ & $72.7(11.5)$ & $73.0(11.0)$ & $72.6(11.3)$ \\
\hline \multicolumn{4}{|c|}{ Income quintile, ${ }^{\mathrm{b}} n(\%)$} \\
\hline 1 - Lowest & $14,036(19.3)$ & $695(20.2)$ & 894 (18.7) \\
\hline 2 & $14,906(20.5)$ & $700(20.3)$ & $932(19.5)$ \\
\hline 3 & $14,376(19.8)$ & 707 (20.6) & 947 (19.9) \\
\hline 4 & $14,317(19.7)$ & $646(18.8)$ & $961(20.2)$ \\
\hline 5 - Highest & $15,169(20.8)$ & $693(20.1)$ & 1036 \\
\hline \multicolumn{4}{|l|}{ Residence, $^{\mathrm{b}} n(\%)$} \\
\hline Urban & $63,204(86.6)$ & $2939(85.1)$ & $4196(86.8)$ \\
\hline Rural & $9814(13.4)$ & $514(14.9)$ & $585(12.2)$ \\
\hline \multicolumn{4}{|c|}{ Onset of parkinsonism, ${ }^{\mathrm{c}} n(\%)$} \\
\hline Young onset & $1016(1.4)$ & $41(1.2)$ & $37(0.8)$ \\
\hline Mid/late onset & $72,113(98.6)$ & $3420(98.9)$ & $4754(99.2)$ \\
\hline
\end{tabular}

${ }^{\mathrm{a}}$ Fiscal year starts on April 1.

${ }^{\mathrm{b}}$ Percentages do not add up to $100 \%$ due to missing values.

${ }^{\mathrm{c}}$ Young onset is $20-39$ years of age; mid/late onset is $\geq 40$ years of age. $\mathrm{SD}=$ standard deviation

\section{Age- and Sex-Standardized Prevalence of Risk Factors among Persons with Parkinsonism}

Among individuals with newly diagnosed parkinsonism, the prevalence of the following risk factors decreased over the four epochs: COPD $(-53.0 \% ; p<0.0001)$, stroke $(-51.2 \%$; $p=0.0008)$, coronary artery disease $(-41.7 \% ; p=0.0265)$, and congestive heart failure $(-27.6 \% ; p=0.0027)$ (Figure 2). There was no statistically significant decrease in the prevalence of traumatic brain injury. Conversely, the prevalence of diabetes increased by $99.3 \%$, dementia increased by $31.0 \%$, and hypertension increased by $29.5 \%(p<0.0001)$ over the four epochs. Further adjustment for these risk factors among persons with parkinsonism and the general population had little influence on the declining trend in the incidence of mid/late-onset parkinsonism (Supplementary File). Similarly, adjustment for rural living among persons with parkinsonism and prevalence of other factors (smoking and pesticide use) among the general population had little influence on the declining incidence of mid/late-onset parkinsonism (Supplementary File).

\section{Discussion}

In Ontario, Canada's most populous province, the age- and sex-standardized incidence of parkinsonism decreased, prevalence increased, and mortality decreased from 1996 to 2014.
However, there were differing rates in incidence when stratified by young-onset and mid/late-onset parkinsonism. The incidence for mid/late-onset parkinsonism decreased over time but was unchanged for young-onset parkinsonism, as might be expected for a group more likely to have genetic parkinsonism. ${ }^{10,11}$ Adjustment for a number of risk factors for brain health conditions did not account for the declining trend in incidence of $\mathrm{mid} /$ late-onset parkinsonism.

Several previous studies have examined the trends of incidence in parkinsonism. Among them, three studies reported relatively stable incidence rates in the USA and Manitoba, Canada, but two reported increasing incidence rates in the USA and Finland. ${ }^{12,13,17-19} \mathrm{We}$ found decreasing trends in the incidence of mid/late-onset parkinsonism, which provides support to four other smaller studies suggesting decreasing incidence rates in USA, UK, the Netherlands, and Taiwan. ${ }^{14-16,20}$ Our finding of a relatively unchanged incidence for young-onset parkinsonism suggests that genetic forms may be less prone to change over time. ${ }^{10,11}$ When stratified by sex, our findings are similar to previous studies that reported a more considerable decline in parkinsonism incidence rates among women over time compared to that among men. ${ }^{17,20}$

Our study used a previously validated algorithm to identify patients with parkinsonism. ${ }^{32}$ This previous study used a reference standard drawn from a primary care population, which had a proportion of Parkinson's disease to parkinsonism of $82.7 \% .{ }^{32}$ In the UK, a previous study reported decreasing incidence of Parkinson's disease over time, but not parkinsonism. ${ }^{14}$ Despite the trends in declining incidence found in our study, we were unable to determine whether similar trends were found for parkinsonism versus Parkinson's disease.

For prevalence, our results add further weight to a handful of previous studies suggesting an increasing trend in prevalence. $^{13,16,21,32}$ This coincided with a decreasing trend in mortality (by $5.5 \%$ ) among individuals with parkinsonism found in our study and several previous studies. ${ }^{22-24}$ In contrast, the standardized mortality rate of the Ontario population from 2000 to 2012 declined by approximately 19\% (compared to $5.5 \%$ among persons with parkinsonism in Ontario). ${ }^{42}$ The ever increasing prevalence underscores the need to focus public health services on improving prognosis, advancing pharmacological and nonpharmacological treatment options, as well as appropriately allocating resources and facilities for patients living with parkinsonism.

Our observation of a declining incidence of mid/late-onset parkinsonism presents an opportunity to investigate drivers of the time trend and guide primary prevention strategies targeting risk factor control. We found that adjusting for known risk factors for brain health did not appreciably account for the declining incidence trends. This decline in incidence is similar to other reported declines in neurodegenerative pathologies, such as Alzheimer's disease, that have been noted in affluent countries, and may reflect improved general health among other possible factors. ${ }^{25,44-46}$

Our study has several strengths. First, it involved a large cohort (73,129 incident cases from a source population of 10.5 million in 2013) over nearly two decades. Ontario is the most populous and ethnically diverse province in Canada, with more than 200 ethnic origins represented. ${ }^{42}$ Second, we compared trends between young-onset and mid/late-onset parkinsonism. ${ }^{8,9}$ Previous literature suggests that there are etiologic and prognostic differences 
Table 3: Crude, and age- and sex-standardized ${ }^{\mathrm{a}}$ incidence, prevalence, and post-diagnosis mortality parkinsonism (including Parkinson's disease) in 1996/97, 2002/03, $2007 / 08$, and $2013 / 14^{\text {b }}$, by young-onset (20-39 years) and mid/late onset ( $\geq 40$ years)

\begin{tabular}{|c|c|c|c|c|c|c|c|c|c|c|c|c|}
\hline & \multicolumn{3}{|c|}{$1996 / 97$} & \multicolumn{3}{|c|}{$2002 / 03$} & \multicolumn{3}{|c|}{ 2007/08 } & \multicolumn{3}{|c|}{ 2013/14 } \\
\hline & All & $\begin{array}{l}\text { Young } \\
\text { onset }\end{array}$ & $\begin{array}{c}\text { Mid/ } \\
\text { late-onset }\end{array}$ & All & $\begin{array}{l}\text { Young } \\
\text { onset }\end{array}$ & $\begin{array}{c}\mathrm{Mid} / \\
\text { late onset }\end{array}$ & All & $\begin{array}{l}\text { Young } \\
\text { onset }\end{array}$ & $\begin{array}{c}\text { Mid/ } \\
\text { late onset }\end{array}$ & All & $\begin{array}{l}\text { Young } \\
\text { onset }\end{array}$ & $\begin{array}{c}\text { Mid/ } \\
\text { late onset }\end{array}$ \\
\hline \multicolumn{13}{|c|}{ Incidence (per 100,000 person-years) } \\
\hline $\begin{array}{l}\text { Number of } \\
\text { incident } \\
\text { cases }\end{array}$ & 3461 & 41 & 3420 & 3810 & 61 & 3749 & 4199 & 55 & 4144 & 4791 & 37 & 4754 \\
\hline Person-years & $8,089,254.6$ & $3,530,313.1$ & $4,558,941.5$ & $8,934,354.7$ & $3,541,234.5$ & $5,393,120.2$ & $9,615,904.9$ & $3,507,193.9$ & $6,108,711.0$ & $10,430,961.1$ & $3,653,273.8$ & $6,777,687.2$ \\
\hline $\begin{array}{l}\text { Crude } \\
\text { incidence }\end{array}$ & 42.8 & 1.2 & 75.0 & 42.6 & 1.7 & 69.5 & 43.7 & 1.6 & 67.8 & 45.9 & 1.0 & 70.1 \\
\hline $\begin{array}{c}\text { Age- and sex- } \\
\text { standardized } \\
\text { incidence }\end{array}$ & 45.3 & 1.2 & 75.0 & 42.7 & 1.7 & 70.2 & 41.3 & 1.6 & 68.0 & 39.4 & 1.1 & 65.2 \\
\hline \multicolumn{13}{|c|}{ Prevalence (per 1000 persons) } \\
\hline $\begin{array}{l}\text { Number of } \\
\text { prevalent } \\
\text { cases }\end{array}$ & 19,833 & 225 & 19,608 & 26,417 & 539 & 25,878 & 30,965 & 803 & 30,162 & 37,100 & 1087 & 36,013 \\
\hline Population $^{\mathrm{b}}$ & $8,107,876$ & $3,530,470$ & $4,577,406$ & $8,959,835$ & $3,541,562$ & $5,418,273$ & $9,646,421$ & $3,507,611$ & $6,138,810$ & $10,468,051$ & $3,653,768$ & $6,814,283$ \\
\hline $\begin{array}{l}\text { Crude } \\
\text { prevalence }\end{array}$ & 2.4 & 0.1 & 4.3 & 3.0 & 0.2 & 4.8 & 3.2 & 0.2 & 4.9 & 3.5 & 0.3 & 5.3 \\
\hline $\begin{array}{c}\text { Age- and sex- } \\
\text { standardized } \\
\text { prevalence }\end{array}$ & 2.5 & 0.1 & 4.2 & 2.9 & 0.2 & 4.8 & 3.1 & 0.2 & 5.0 & 3.1 & 0.3 & 5.0 \\
\hline \multicolumn{13}{|c|}{ Mortality (per 1000 person-years) } \\
\hline $\begin{array}{c}\text { Number of } \\
\text { deaths }\end{array}$ & 2298 & 6 & 2292 & 2776 & 6 & 2770 & 3106 & $\mathrm{NA}^{\mathrm{c}}$ & 3101 & 3399 & 7 & 3392 \\
\hline Person-years & $22,238.5$ & 262.7 & $21,975.9$ & $28,903.6$ & 596.5 & $28,307.1$ & $33,713.2$ & $\mathrm{NA}^{\mathrm{c}}$ & $32,857.3$ & $40,261.9$ & 1120.3 & $39,141.6$ \\
\hline $\begin{array}{l}\text { Crude } \\
\text { mortality }\end{array}$ & 103.3 & 22.8 & 104.3 & 96.0 & 10.1 & 97.9 & 92.1 & 5.8 & 94.4 & 84.4 & 6.2 & 86.7 \\
\hline $\begin{array}{l}\text { Age- and sex- } \\
\text { standardized } \\
\text { mortality }\end{array}$ & 90.8 & 21.4 & 92.5 & 92.6 & 9.7 & 94.7 & 91.9 & 5.9 & 94.0 & 85.8 & 6.4 & 87.8 \\
\hline
\end{tabular}

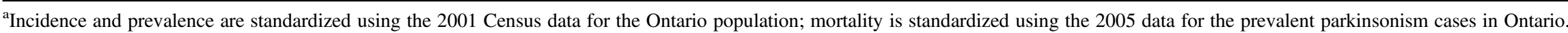
${ }^{\mathrm{b}}$ Fiscal year starts on April 1.

${ }^{\mathrm{c}} \mathrm{NA}=$ not available due to cell sizes $\leq 5$ (not reported to protect confidentiality of subjects). 


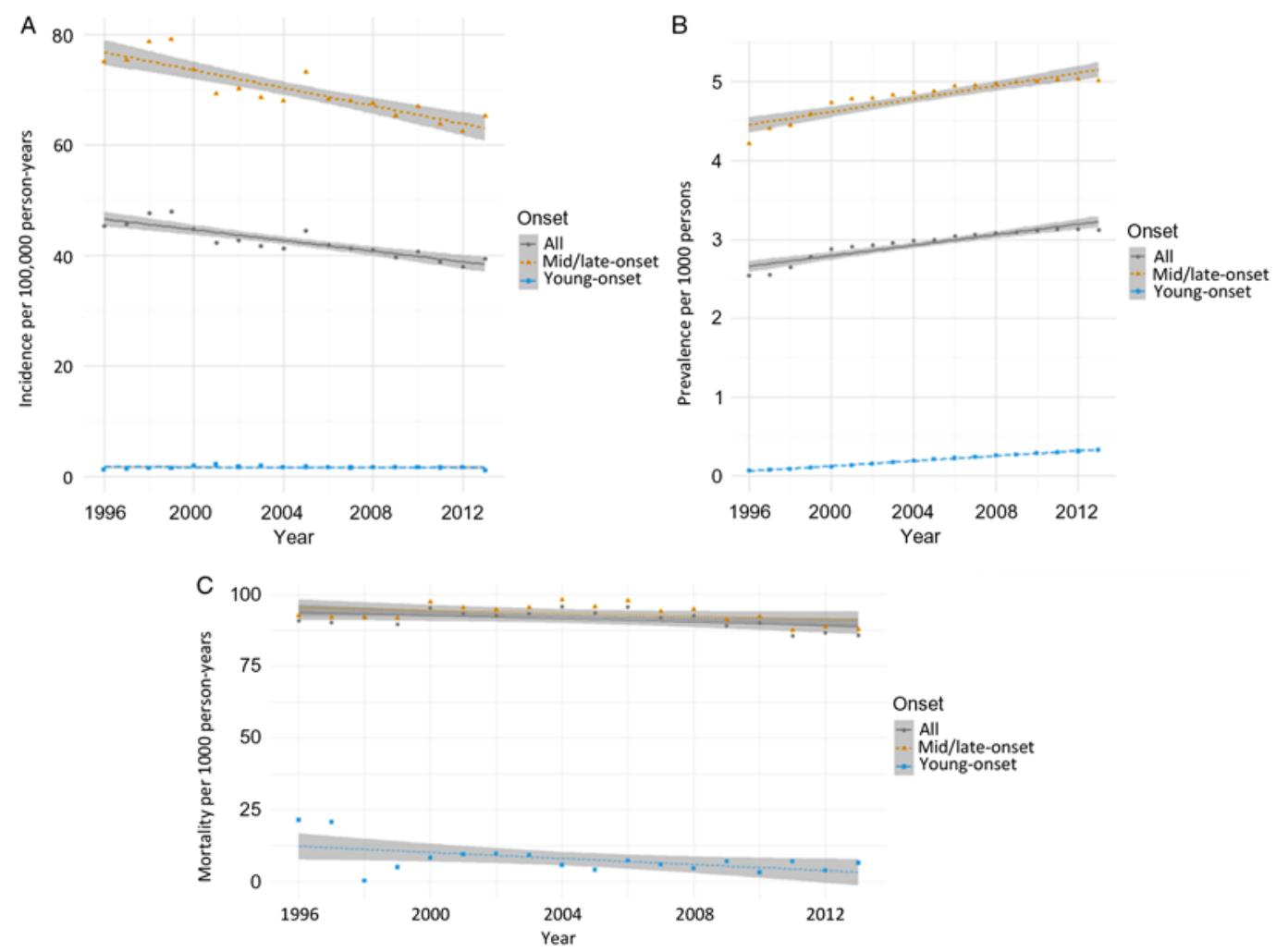

Figure 1: Age-and sex-standardized (incidence and prevalence are standardized using the 2001 Census data for the Ontario population; mortality is standardized using the 2005 data for the prevalent parkinsonism cases in Ontario) incidence (A), prevalence $(B)$, and post-diagnosis mortality $(C)$ of parkinsonism from 1996/97 to 2013/14, by young onset (20-39 years) and mid/late onset $(\geq 40$ years) (Figure 1A (incidence): all, $p<0.0001 ;$ young onset, $p=0.7341$; mid/late onset, $p<0.0001$. Figure $1 B$ (prevalence): all, $p<0.0001$; young onset, $p<0.0001$; mid/late onset, $p<0.0001$. Figure 1C (mortality i.e., all deaths among persons with parkinsonism): all, $p=0.0180 ;$ young onset, $p=0.0024 ;$ mid/late onset, $p=0.0283$ ).
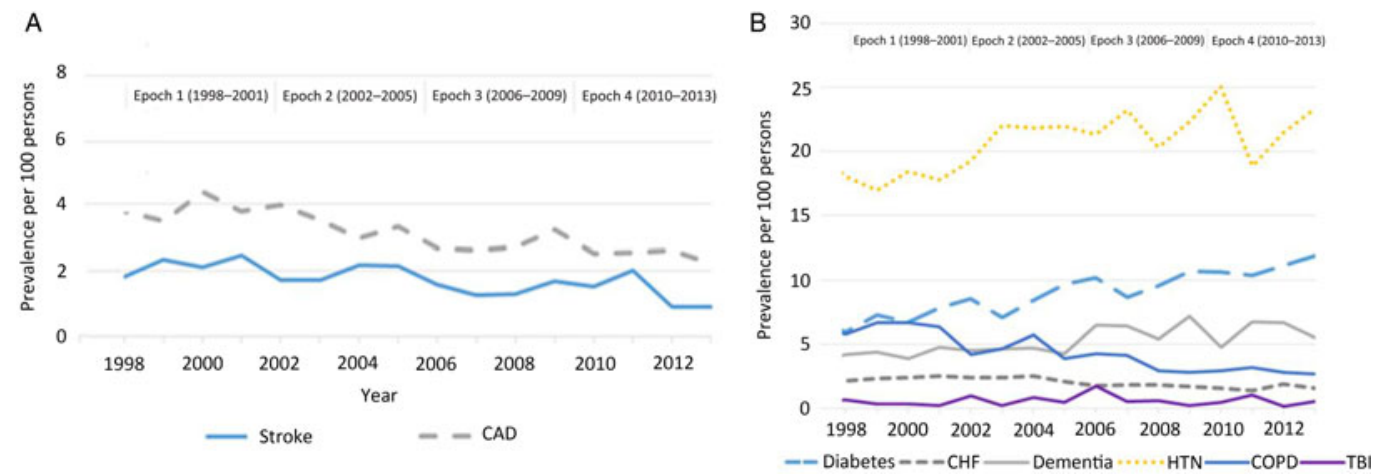

Figure 2: Age- and sex-standardized (standardized using the 2001 Census data for the Ontario Population) prevalence of risk factors ascertained using CIHI hospitalization data $(A)$ and algorithms $(B)$ among persons with parkinsonism from 1998/99 to 2013/14 (Figure 2A: coronary artery disease, $p=0.0265$; stroke, $p=0.0008$. Figure $2 B$ : congestive heart failure, $p=0.0027$; COPD, $p<0.0001$; dementia, $p<0.0001$; diabetes, $p<0.0001$; hypertension, $p<0.0001$; traumatic brain injury, $p=0.3047)$. Acronyms: $C A D=$ coronary artery disease; $C H F=$ congestive heart failure $; C I H I=$ Canadian Institute for Health Information; $C O P D=$ chronic obstructive pulmonary disease; HTN = hypertension; TBI= traumatic brain injury.

related to the timing of disease onset. ${ }^{8,9}$ Third, we examined the prevalence of selected pre-existing conditions among persons with parkinsonism, which allows us to gain important insights about potential risk factors. Finally, we used population-based health administrative databases with a validated algorithm to ascertain parkinsonism cases. ${ }^{32}$ This algorithm has a relatively high accuracy. ${ }^{32}$ Most risk factors were also identified using validated algorithms with high sensitivity and specificity.

Our study has some limitations. Using health administrative databases may not capture individuals without clinically recognized 
symptoms and those who have not yet sought health care. As well, the less than $100 \%$ sensitivity of the algorithm for parkinsonism may have underestimated its incidence and prevalence. In addition, despite using the entire Ontario population, this study may still have been underpowered to detect significant trends in young-onset parkinsonism ( $\sim 1 \%$ of incident cases). Nevertheless, stratified estimates of trends for the two groups can have clinical implications for etiology and prognosis of this important disease. ${ }^{8,9}$ Although we know the proportion $(82.7 \%)$ of patients with parkinsonism to Parkinson's disease in the reference standard for the validation of the administrative data algorithm ${ }^{32}$ used in this study, we are unable to precisely identify the proportion in Ontario using administrative data. This is because the OHIP data only has one billing code that includes both Parkinson's disease and parkinsonism. However, while parkinsonism encompasses different subtypes, Parkinson's disease makes up the majority of cases (up to 80\%). ${ }^{47,48}$ Nonetheless, we were unable to distinguish between subtypes of parkinsonism, and some risk factors may differ among the subtypes. Finally, we were unable to ascertain other accepted or suspected risk factors (e.g., family history, drug exposure, depressive symptoms, and sleep complaints) for parkinsonism. ${ }^{33,49-51}$ Future research is needed to examine the effects of other risk factors on time trends in the incidence of parkinsonism.

\section{ACKNOWLedgements}

This study was supported by Public Health Ontario (PHO) and ICES, which are funded by annual grants from the Ontario Ministry of Health and Long-Term Care (MOHLTC). Parts of this material are based on data and information compiled and provided by Canadian Institute for Health Information (CIHI). The opinions, results, and conclusions reported in this paper are those of the authors and are independent from the funding sources. No endorsement by PHO, ICES, Ontario MOHLTC, or CIHI is intended or should be inferred.

\section{FUNDING}

Funding for this study is provided by Health Canada (MOA4500314182). The funding agency was not involved in the study design, analysis or interpretation of data, in the writing of the report, or in the decision to submit the paper for publication. JJW is supported by tuition assistance from the Canadian Memorial Chiropractic College. JCK, KT, and DAB are supported by Investigator Awards from the Department of Family and Community Medicine, University of Toronto. JCK is also supported by a New Investigator Award from the Canadian Institutes of Health Research.

\section{Authors' Contributions}

JJW, HC, JCK, KT, and DAB contributed to the study design. JJW, HC, ASW, and AK prepared and cleaned the data. JJW, HC, JCK, KT, DAB, ASW, and AK contributed to the data analyses. JJW took the lead in drafting the manuscript. All authors contributed to interpretation of data, provided critical revisions to the manuscript, and approved the final draft.

\section{Disclosures}

JJW, JCK, KT, DAB, RC, ASW, BJM, AK, and HC report no disclosures.

\section{SuPPlementary MATERIAL}

To view supplementary material for this article, please visit https://doi.org/10.1017/cjn.2018.387.

\section{REFERENCES}

1. Koerts, J, Konig, M, Tucha, L, Tucha, O. Working capacity of patients with Parkinson's Disease - a systematic review. Parkinsonism Relat Disord. 2016;27:9-24.

2. World Health Organization. Global burden of neurological disorders: estimates and projections; 2006. Available at: http://www.who.int/mental_health/neurology/chapter_2_neuro_ disorders public $\mathrm{h}$ challenges.pdf; accessed May 30, 2016.

3. Macleod, AD, Grieve, JW, Counsell, CE. A systematic review of loss of independence in Parkinson's Disease. J Neurol. 2016;263(1): $1-10$.

4. Macleod, AD, Taylor, KS, Counsell, CE. Mortality in Parkinson's Disease: a systematic review and meta-analysis. Mov Disord. 2014;29(13):1615-22.

5. Rodriguez-Blazquez, C, Forjaz, MJ, Lizan, L, Paz, S, MartinezMartin, P. Estimating the direct and indirect costs associated with Parkinson's Disease. Expert Rev Pharmacoecon Outcomes Res. 2015;15(6):889-911.

6. Gustavsson, A, Svensson, M, Jacobi, F, et al. Cost of disorders of the brain in Europe 2010. Eur Neuropsychopharmacol. 2011; 21(10):718-79.

7. Kowal, SL, Dall, TM, Chakrabarti, R, Storm, MV, Jain, A. The current and projected economic burden of Parkinson's Disease in the United States. Mov Disord. 2013;28(3):311-8.

8. World Health Organization. Neurological disorders: public health challenges; 2006. Available at: http://www.who.int/mental_ health/neurology/neurological_disorders_report_web.pdf; accessed August 8, 2016.

9. Grimes, D, Gordon, J, Snelgrove, B, et al. Canadian guidelines on Parkinson's Disease. Can J Neurol Sci. 2012;39(4 Suppl4):S1-30.

10. Marras, C, Lang, A, van de Warrenburg, BP, et al. Nomenclature of genetic movement disorders: recommendations of the international Parkinson and movement disorder society task force. Mov Disord. 2016;31(4):436-57.

11. Schiesling, C, Kieper, N, Seidel, K, Kruger, R. Review: familial Parkinson's Disease - genetics, clinical phenotype and neuropathology in relation to the common sporadic form of the disease. Neuropathol Appl Neurobiol. 2008;34(3):255-71.

12. Akushevich, I, Kravchenko, J, Ukraintseva, S, Arbeev, K, Yashin, AI. Time trends of incidence of age-associated diseases in the US elderly population: medicare-based analysis. Age Ageing. 2013;42(4):494-500.

13. Lix, LM, Hobson, DE, Azimaee, M, Leslie, WD, Burchill, C, Hobson, S. Socioeconomic variations in the prevalence and incidence of Parkinson's Disease: a population-based analysis. J Epidemiol Community Health. 2010;64(4):335-40.

14. Rocca, WA, Bower, JH, McDonnell, SK, Peterson, BJ, Maraganore, DM. Time trends in the incidence of parkinsonism in Olmsted County, Minnesota. Neurology. 2001;57(3):462-7.

15. Horsfall, L, Petersen, I, Walters, K, Schrag, A. Time trends in incidence of Parkinson's Disease diagnosis in UK primary care. J Neurol. 2013;260(5):1351-7.

16. Darweesh, SKL, Koudstaal, PJ, Stricker, BH, Hofman, A, Ikram, MA. Trends in the incidence of Parkinson Disease in the general population. Am J Epidemiol. 2016;183(11):1018-26.

17. Liu, WM, Wu, RM, Lin, JW, Liu, YC, Chang, CH, Lin, CH. Time trends in the prevalence and incidence of Parkinson's Disease in Taiwan: a nationwide, population-based study. J Formos Med Assoc. 2016;115(7):531-8.

18. Savica, R, Grossardt, BR, Bower, JH, Ahlskog, JE, Mielke, MM, Rocca, WA. Incidence and time trends of drug-induced parkinsonism: a 30-year population-based study. Mov Disord. 2017;32(2):227-34.

19. Savica, R, Grossardt, BR, Bower, JH, Ahlskog, JE, Rocca, WA. Time trends in the incidence of Parkinson Disease. JAMA Neurol. 2016;73(8):981-9. 
20. Ylikotila, P, Tiirikka, T, Moilanen, JS, Kääriäinen, H, Marttila, R, Majamaa, K. Epidemiology of early-onset Parkinson's Disease in Finland. Parkinsonism Relat Disord. 2015;21(8):938-42.

21. Goldacre, MJ, Duncan, M, Griffith, M, Turner, MR. Trends in death certification for multiple sclerosis, motor neuron disease, Parkinson's Disease and epilepsy in English populations 1979-2006. J Neurol. 2010;257(5):706-15.

22. Guttman, M, Slaughter, PM, Theriault, ME, DeBoer, DP, Naylor, CD. Burden of parkinsonism: a population-based study. Mov Disord. 2003;18(3):313-9.

23. Mylne, AQ, Griffiths, C, Rooney, C, Doyle, P. Trends in Parkinson's Disease related mortality in England and Wales, 1993-2006. Eur J Neurol. 2009;16(9):1010-6.

24. Griffiths, C, Rooney, C. Trends in mortality from Alzheimer's disease, Parkinson's Disease and dementia, England and Wales, 1979-2004. Health Stat Q. 2006;Summer(30):6-14.

25. Jaakkimainen, RL, Bronskill, SE, Tierney, MC, et al. Identification of physician-diagnosed Alzheimer's disease and related dementias in population-based administrative data: a validation study using family physicians' electronic medical records. J Alzheimers Dis. 2016;54(1):337-49.

26. Chan, B. Supply of physicians' services in Ontario. Hosp Q. 1999; 3(2):17.

27. Chen, H, Kwong, JC, Copes, R, et al. Cohort Profile: the Ontario population health and environment cohort (ONPHEC). Int $\mathbf{J}$ Epidemiol. 2017;46(2):405-j.

28. Tu, K, Chen, Z, Lipscombe, LL. Prevalence and incidence of hypertension from 1995 to 2005: a population-based study. CMAJ. 2008;178(11):1429-35.

29. Gershon, AS, Wang, C, Guan, J, Vasilevska-Ristovska, J, Cicutto, $\mathrm{L}, \mathrm{To}, \mathrm{T}$. Identifying individuals with physician diagnosed COPD in health administrative databases. COPD. 2009;6(5):388-94.

30. Hux, JE, Ivis, F, Flintoft, V, Bica, A. Diabetes in Ontario: determination of prevalence and incidence using a validated administrative data algorithm. Diabetes Care. 2002;25(3):512-6.

31. Schultz, SE, Rothwell, DM, Chen, Z, Tu, K. Identifying cases of congestive heart failure from administrative data: a validation study using primary care patient records. Chronic Dis Inj Can. 2013;33(3):160-6.

32. Butt, DA, Tu, K, Young, J, et al. A validation study of administrative data algorithms to identify patients with Parkinsonism with prevalence and incidence trends. Neuroepidemiology. 2014;43(1):28-37.

33. Breckenridge, CB, Berry, C, Chang, ET, Sielken, RL, Jr., Mandel, JS. Association between Parkinson's Disease and cigarette smoking, rural living, well-water consumption, farming and pesticide use: systematic review and meta-analysis. PLoS One. 2016;11(4): $\mathrm{e} 0151841$.

34. Martino, R, Candundo, H, Lieshout, PV, Shin, S, Crispo, JA, Barakat-Haddad, C. Onset and progression factors in Parkinson's Disease: a systematic review. Neurotoxicology. 2017;61:132-41.

35. Perry, DC, Sturm, VE, Peterson, MJ, et al. Association of traumatic brain injury with subsequent neurological and psychiatric disease: a meta-analysis. J Neurosurg. 2016;124(2):511-26.
36. Zhang, P, Tian, B. Metabolic syndrome: an important risk factor for Parkinson's Disease. Oxid Med Cell Longev. 2014;2014:729194.

37. Becker, C, Jick, SS, Meier, CR. Risk of stroke in patients with idiopathic Parkinson Disease. Parkinsonism Relat Disord. 2010;16(1):31-5.

38. Li, CH, Chen, WC, Liao, WC, et al. The association between chronic obstructive pulmonary disease and Parkinson's Disease: a nationwide population-based retrospective cohort study. QJM. 2015;108(1):39-45.

39. Wirdefeldt, K, Adami, HO, Cole, P, Trichopoulos, D, Mandel, J. Epidemiology and etiology of Parkinson's Disease: a review of the evidence. Eur J Epidemiol. 2011;26(Suppl1):S1-58.

40. Farm \& Food Care Ontario. Survey of pesticide use in Ontario, 2013/2014. Estimates of pesticides used on field crops and fruit and vegetable crops; 2015. Available at: http://www.farmfood careon.org/wp-content/uploads/2016/10/ONTARIO-Pesticide-UseSurvey-Final-2013.pdf; accessed December 1, 2017.

41. Ng, R, Maxwell, CJ, Yates, EA, et al. Brain disorders in Ontario: prevalence, incidence and costs from health administrative data. Toronto, ON: Institute for Clinical Evaluative Sciences; 2015.

42. Statistics Canada. 2001 Census of Canada; 2018. Available at: http:// www12.statcan.ca/english/census01/home/Index.cfm; accessed July $15,2016$.

43. Gardner, W, Mulvey, EP, Shaw, EC. Regression analyses of counts and rates: Poisson, overdispersed Poisson, and negative binomial models. Psychol Bull. 1995;118(3):392-404.

44. Langa, KM. Is the risk of Alzheimer's disease and dementia declining? Alzheimers Res Ther. 2015;7(1):34. doi: 10.1186/ s13195-015-0118-1.

45. Schrijvers, EM, Verhaaren, BF, Koudstaal, PJ, Hofman, A, Ikram, MA, Breteler, MM. Is dementia incidence declining?: trends in dementia incidence since 1990 in the Rotterdam Study. Neurology. 2012;78(19):1456-63.

46. Langa, KM, Larson, EB, Crimmins, EM, et al. A comparison of the prevalence of dementia in the United States in 2000 and 2012. JAMA Intern Med. 2017;177(1):51-8.

47. Schrag, A, Ben-Shlomo, Y, Quinn, NP. Cross sectional prevalence survey of idiopathic Parkinson's Disease and Parkinsonism in London. BMJ. 2000;321(7252):21-2.

48. International Parkinson and Movement Disorder Society. Parkinson's Disease \& Parkinsonism; 2018. Available at: https://www. movementdisorders.org/MDS/About/Movement-Disorder-Overviews/ Parkinsons-Disease-Parkinsonism.htm; accessed October 23, 2018.

49. Ascherio, A, Schwarzschild, MA. The epidemiology of Parkinson's Disease: risk factors and prevention. Lancet Neurol. 2016;15(12): 1257-72.

50. Thanvi, B, Treadwell, S. Drug induced parkinsonism: a common cause of parkinsonism in older people. Postgrad Med J. 2009; 85(1004):322-6.

51. Buchman, AS, Leurgans, SE, Yu, L, et al. Incident parkinsonism in older adults without Parkinson Disease. Neurology. 2016; 87(10):1036-44. 